\title{
A percepção de emoções em trechos de música ocidental erudita'
}

\author{
Danilo Ramos (UFPR, Curitiba, PR) \\ danramosnilo@gmail.com \\ José Lino Oliveira Bueno (USP, Ribeirão Preto, SP) \\ jldobuen@usp.br
}

Resumo: 0 objetivo deste estudo foi verificar respostas emocionais a trechos musicais do repertório erudito ocidental. Músicos e não músicos ouviam cada trecho musical e associavam-no a categorias emocionais (Alegria, Tristeza, Serenidade ou Medo/Raiva). Os resultados indicaram que, para ambos os grupos, cada trecho musical, na maioria, não foi associado a mais de uma categoria emocional. De um modo geral, as associações foram semelhantes entre os grupos, embora as respostas dos músicos tenham sido mais consistentes. Estes resultados sugerem um processamento cognitivo de respostas emocionais à música ocidental relacionado à estrutura cognitiva do evento, a diferenças entre indivíduos e à expertise musical.

Palavras-chave: Emoções musicais; Percepção musical; Expertise musical.

\section{The perception of emotions in excerpts of classical Western music}

Abstract: The aim of this study was to evaluate emotional responses to musical excerpts from Western repertoire. Musicians and nonmusicians listened to each musical excerpt and linked it to emotional categories (Joy, Sadness, Serenity or Fear / Anger). The results indicated that each musical excerpt, in majority, was not associated to more than one emotional category, for both groups. In general, associations were similar between groups, although the responses of musicians have been more consistent. These results suggest a cognitive processing of emotional responses to music related to the cognitive structure of the event, to individual differences and to musical expertise.

Keywords: Musical emotions; Music perception; Musical expertise.

\section{1 - Introdução}

Vários estudos têm sido desenvolvidos no intuito de mensurar as emoções desencadeadas durante uma escuta musical (por exemplo: GABRIELSSON; JUSLIN, 2003; GABRIELSSON; JUSLIN, 2001; GABRIELSSON, 2001; ROBINSON, 1997; SLOBODA; JUSLIN, 2001). Os resultados destas pesquisas mostraram que os ouvintes percebem as emoções musicais de forma coerente, ou seja, têm sido observados altos índices de associações emocionais equivalentes para músicas iguais. Esta coerência foi encontrada em adultos e crianças (DALLA BELLA; PERETZ; ROUSSEAU; GOSSELIN; AYOTTE; LAVOIE, 2001), bem como entre participantes de diferentes culturas (BALKWILL; THOMPSON, 1999). Foram feitas, também, comparações de respostas emocionais a trechos musicais idênticos pelos mesmos participantes após várias semanas - teste/reteste (BIGAND; VIEILLARD; MADURELL; MAROZEAU; DACQUET, 2005). Apesar de a nova estética experimental proposta por BERLYNE (1974) considerar as diferenças entre indivíduos como um fator que pode determinar o caráter das respostas subjetivas a estímulos artísticos, os resultados acima reforçam a ideia de que as emoções musicais possam depender também da cognição dos elementos da estrutura musical da própria obra (BIGAND et al., 2005).

Segundo JØRGENSEN (1988), existem diversas maneiras através das quais a música pode expressar e evocar as emoções aos ouvintes: os cientistas devem observar que 0 que pode ser levado em conta para uma fonte específica de emoção pode não ser levado em conta para outra e que diferentes teorias podem ser requeridas. Assim, estas diferentes fontes envolvem e são influenciadas por um número grande de variáveis em música, pela pessoa e pela situação. Esta complexidade torna extremamente necessária a atenção dos pesquisadores na seleção de variáveis para seus objetos de estudo. Também, e, consequentemente, é importante que os pesquisadores estejam conscientes de que, após selecionar algumas variáveis causais estão deixando outras de lado (JUSLIN; LAUKKA, 2004).

Existem diversas metodologias sobre a mensuração da percepção das emoções durante uma experiência de escuta musical: medidas comportamentais (análise das 
manifestações comportamentais expressas pelo ouvinte, mensuradas por meio da exteriorização de padrões comportamentais), medidas cognitivas (análise dos relatos verbais dos participantes durante ou após a escuta de um evento musical, mensurados por meio de testes de escolha forçada, lista de adjetivos, taxas emocionais ou descrições livres) e/ou medidas psicofisiológicas (análise das alterações fisiológicas dos participantes durante ou após uma escuta musical, mensuradas por meio de batimento cardíaco, resposta galvânica da pele ou registros gráficos das correntes elétricas geradas no encéfalo do participante no momento da escuta musical, por meio de aparelhos como eletroencefalograma).

O Modelo Circumplexo de RUSSEL $(1979,1980)$ é uma possibilidade que a literatura científica reconhece para o estudo das respostas emocionais à música. Trata-se de uma estrutura distribuida em um referencial cartesiano, baseada em duas dimensões: arousal e valência afetiva. 0 arousal (ou estado de excitação fisiológica) é mensurado a partir da premissa de que toda escuta musical provoca no participante uma espécie de estado de préativação interna, em que mecanismos neurais e cognitivos são ativados, levando o participante a prestar atenção à música que está sendo executada. 0 arousal chega a provocar até mesmo reações motoras nos participantes, como bater o pé ou as mãos para imitar o acompanhamento da música, dançar, entre outros comportamentos. A valência afetiva (ou valor hedônico) é mensurada a partir da premissa de que toda música carrega em si um valor afetivo, que pode variar de pessoa para pessoa; podemos ficar em um determinado estado emocional durante uma escuta musical, dependendo de nossas diferenças individuais, oriundas de nossos diferentes valores culturais (adquiridos a partir do meio em que vivemos) e biológicos (inatos, que se referem ao conteúdo genético transmitido de geração a geração). A valência afetiva, portanto, refere-se ao grau de satisfação desencadeado no ouvinte durante uma escuta musical. Segundo o Modelo Circumplexo de RUSSEL (1980), cada uma destas duas dimensões (arousal e valência) pode ser positiva ou negativa, o que dá origem a quatro quadrantes dentro do referencial cartesiano, cada um dos quais representado por categorias emocionais semelhantes. Por exemplo: em um quadrante no qual o arousal é alto e a valência afetiva é positiva, encontram-se categorias emocionais relacionadas à Alegria e à Excitação; em um quadrante no qual o arousal é alto, mas a valência afetiva é negativa, encontram-se categorias emocionais relacionadas ao Medo e à Raiva; em um quadrante no qual o arousal é baixo, mas a valência afetiva é positiva, encontram-se categorias emocionais relacionadas ao Relaxamento e à Serenidade; em um quadrante no qual o arousal é baixo e a valência afetiva é negativa, encontram-se categorias emocionais relacionadas à Tristeza e à Sonolência (para maiores detalhes sobre a estrutura bidimensional do Modelo Circumplexo de Russel, ver sessão Resultados do presente trabalho). Há uma série de estudos que utilizam medidas de arousal e de valência afetiva para mensurar as emoções desencadeadas durante uma escuta musical (RUSSEL, 1980; BIGAND et al., 2005; RAMOS; BUENO; BIGAND, 2011; COCENAS-SILVA; BUENO; MOLIN; BIGAND, 2011). Este modelo fornece uma maneira eficaz de organizar as emoções em termos do afeto (agradável ou desagradável) e das reações fisiológicas (excitação elevada ou baixa), e, além disso, especifica uma maneira de selecionar adjetivos a serem utilizados como medidas de emoção na investigação (LARSEN; DIENER, 1992; SLOBODA; JUSLIN, 2001). A maioria das pesquisas experimentais sobre as emoções musicais tem utilizado o Modelo Circumplexo de RUSSEL (1979, 1980) como parâmetro utilizado na seleção de categorias emocionais associadas a escuta musical. Este modelo permitiu identificar cinco categorias emocionais principais para os estudos a serem desenvolvidos sobre respostas emocionais à música: Alegria, Serenidade, Raiva, Medo e Tristeza (RUSSEL, 1980). Segundo JUSLIN e LAUKKA (2004), estas emoções são desencadeadas mais rapidamente durante uma escuta musical e por isso foram denominadas emoções musicais de base.

As pesquisas que mensuram as emoções musicais revelam que a percepção de uma emoção musical depende também de fatores como a forma da resposta, o procedimento da pesquisa e o tipo de sujeito analisado (SLOBODA; JUSLIN, 2001). Neste sentido, os estudos que procuram verificar a influência da expertise musical sobre as respostas emocionais têm mostrado que músicos processam a informação emocional de forma mais "refinada" do que não músicos e, portanto, há mais consistência nas respostas emocionais dos músicos em relação às respostas emocionais dos não músicos. Isso significa que maiores são as chances de um mesmo trecho musical estar associado a uma única emoção em uma amostra de músicos do que em uma amostra de não músicos. Considerando a expertise musical, definida como a aquisição progressiva do estudo sistematizado de algum instrumento musical (GALVÃO, 2006), aparentemente, os músicos percebem uma emoção de forma parecida com os não músicos. Em um estudo realizado por BIGAND et al., (2005), músicos e não músicos ouviram 27 trechos de composições eruditas do repertório ocidental, cada uma com 20 segundos de duração, selecionadas para desencadear emoções de base - Alegria, Tristeza, Raiva ou Serenidade - e também emoções mais sutis. A tarefa experimental consistia em reagrupar os trechos musicais característicos de uma mesma emoção, definindo assim categorias emocionais sem recorrer à linguagem verbal, no intuito de abrir mão de um léxico emocional que se sabe variável em função do nível de conhecimento musical e das aptidões verbais de cada um. Duas semanas depois da realização do experimento, os mesmos participantes refizeram a tarefa com os mesmos trechos musicais. Os resultados indicaram que as respostas emocionais às músicas apresentadas foram semelhantes entre os músicos e os não músicos. As principais emoções categorizadas foram: Alegria, Tristeza, Serenidade, Medo e Raiva. No entanto, apesar das respostas emocionais 
terem sido semelhantes, houve maior homogeneidade de respostas dos músicos para cada música apresentada em relação aos não músicos.

0 objetivo do presente estudo foi o de verificar respostas emocionais de músicos e não músicos sobre trechos musicais do repertório erudito ocidental. Levando-se em conta que o contexto é relevante para a apreciação musical (BALKWILL; THOMPSON, 1999), este estudo deve trazer informações sobre a percepção das emoções musicais no contexto brasileiro.

\section{2- 0 Método}

Participantes: 16 estudantes de um curso de graduação em Música, que tinham pelo menos seis anos de experiência de estudo sistematizado de piano, violão, violino, viola, violoncelo, contrabaixo, flauta transversal, clarineta, trombone ou saxofone (classificados neste estudo como músicos) e 16 participantes que não tinham nenhuma experiência em estudo de Música (classificados neste estudo como não músicos). Todos os participantes tinham entre 18 e 28 anos de idade (média $=23,4$ anos). Ambos os grupos (músicos e não músicos) eram formados por 8 homens e 8 mulheres. Todos relataram não apresentar problemas de audição.

Equipamento e material: o estudo foi realizado em uma sala de estudos silenciosa, iluminada por lâmpadas fluorescentes e com paredes lisas, sem estímulos visuais que pudessem interferir nas tarefas dos participantes. 0 espaço interno da sala era preenchido por uma mesa, três cadeiras (uma para o experimentador e as outras duas para os participantes). Sobre a mesa havia dois notebooks (Pentium INTEL), que eram utilizados para apresentação das músicas e para o registro dos julgamentos emocionais, por meio do programa Emmusic. Conectado a cada notebook havia um fone de ouvido Koss R80 (Signus- Philadélfia, EUA), utilizado pelos participantes para a apreciação das músicas. A disposição dos notebooks na mesa era feita de tal forma que a tarefa de um participante não pudesse interferir na tarefa de outro; assim, os participantes realizavam as suas tarefas experimentais de costas, um para o outro. Fora da sala experimental, havia duas mesas e duas cadeiras ocupadas pelos participantes para o preenchimento de um questionário complementar, contendo perguntas relacionadas a dados pessoais, ao grau de conhecimento musical dos participantes e ao próprio estudo.

Caracterização do material musical: os trechos empregados tiveram a duração de 36 segundos, considerada adequada para uma percepção e identificação de emoções especificas. Foram selecionados 30 trechos de obras do repertório erudito ocidental, seguindo os critérios estabelecidos por JUSLIN e LAUKKA (2004). A utilização de músicas conhecidas (por exemplo: As quatro estações, de Vivaldi) foi evitada. A intensidade na faixa de frequência média de cada estímulo foi de $50 \mathrm{~dB}$ (confortável para os participantes). Cada trecho musical tinha 36 segundos de duração. Os títulos de cada obra encontram-se no Ex.1.

\begin{tabular}{|c|c|c|}
\hline Música & Título da obra & Compositor \\
\hline 01 & Also sprach Zarathustra & R. Strauss \\
\hline 02 & Waltz Op. 70, no 3 & F. Chopin \\
\hline 03 & Piano Concerto K 488 (adágio) & W. Mozart \\
\hline 04 & Violin Concerto (adágio) & J. Brahms \\
\hline 05 & Sonata $(A)$ for harpsichord $K 208$ & D. Scarlatti \\
\hline 06 & Träumerei, Op. 15, $n^{\circ} 7$ & R. Schumann \\
\hline 07 & Sonata for piano Op. $18, n^{\circ} 3$ & D. Prokofièv \\
\hline 08 & Trio 2 for piano, violin and cello (largo) & D.Shostakovitch \\
\hline 09 & Tristan, act 3 & R. Wagner \\
\hline 10 & Symphony Bdur, Hob 1, 105 (andante) & J. Haydn \\
\hline 11 & Poème Symphonique & F. Liszt \\
\hline 12 & Gnossiènne $n^{\circ} 2$ & E. Satie \\
\hline 13 & Hungarian Rapsody $n^{\circ} 2$ & F. Liszt \\
\hline 14 & That certain feeling & G. Gershwin \\
\hline 15 & Italian Symphony, $1^{\text {st }}$ movement & F. Mendelsohn \\
\hline 16 & Prelude $n^{\circ} 24$ & F. Chopin \\
\hline 17 & Tasso Lamento \& Triomfo & F. Liszt \\
\hline 18 & Tod und Verklärung (7' to 7'36) & R. Strauss \\
\hline 19 & Violin Sonata & J.S. Bach \\
\hline 20 & Scherzo - A truta (presto) & F. Schubert \\
\hline 21 & Suïte française $G$ (sarabande) & J.S. Bach \\
\hline 22 & Duetto for two flutes in F(lamentgbile) & J. S. Bach \\
\hline 23 & Trio for piano, violin and horn, $2^{\text {nd }}$ movement (moderato) & J. Brahms \\
\hline 24 & Petrouchka & I. Stravinsky \\
\hline 25 & Erwartung & A. Schöenberg \\
\hline 26 & Trio 2 for violin, cello and piano (moderato) & D. Shostakovitch \\
\hline 27 & Totentanz & F. Liszt \\
\hline 28 & O tambor dos granadeiros & R. Chapí \\
\hline 29 & Violin romance & L. V. Beethoven \\
\hline 30 & Valse in E minor - póstuma (vivace) & F. Chopin \\
\hline
\end{tabular}

Ex.1 - Tabela com trechos musicais empregados no presente estudo. 
Procedimento: foi utilizado um teste de escolha forçada, visando facilitar a tarefa de identificação das respostas emocionais. As categorias emocionais empregadas foram selecionadas a partir do Modelo Circumplexo de RUSSEL (1980), com o emprego de medidas de arousal e valência afetiva. No início da sessão experimental, cada participante recebia as seguintes instruções: "Você vai realizar uma tarefa de julgamentos emocionais sobre as músicas que você irá ouvir. Primeiramente, você deverá colocar este fone de ouvido e acomodá-lo adequadamente. $\mathrm{Na}$ tela deste notebook existem ícones, cujos nomes estão enumerados de 1 a 30 . Cada ícone corresponde a uma música. Você deverá, então, com a ajuda do mouse, escolher um ícone por vez, aleatoriamente. Quando você teclar no ícone escolhido, então soará a música referente a este ícone. Você deverá escutá-la até o seu fim, em silêncio. Quando a música acabar, aparecerá uma caixa de texto e você terá duas opções: a primeira opção indica a repetição do mesmo trecho musical; a segunda opção indica que você está pronto para realizar a associação deste trecho musical a uma emoção. Se você escolher a primeira opção, o mesmo trecho musical será repetido; se você escolher a segunda opção, abrirá uma caixa de textos com as opções Alegria, Serenidade, Tristeza ou Medo/Raiva. Você então, com a ajuda do mouse, deverá escolher uma destas categorias. Dessa forma, você terá feito uma associação da música ouvida anteriormente a uma categoria emocional. Quando você terminar de fazer a sua associação emocional ao trecho musical escolhido, a tela inicial com os ícones referentes a cada música se abrirá novamente, mas com o ícone escolhido anteriormente apagado (para que você não o escolha novamente). Você, então, deverá realizar as associações emocionais da mesma forma com as outras 29 músicas. Você poderá escutar uma mesma música quantas vezes achar necessário. Quando você fizer a tarefa de associação das emoções com a última música, aparecerá uma mensagem de agradecimento na tela do notebook, significando o término do estudo". As categorias emocionais eram apresentadas em ordem aleatória, após a audição dos trechos musicais. Terminado o estudo, os participantes eram encaminhados para fora da sala experimental para o preenchimento dos questionários complementares, que continham perguntas referentes a informações pessoais sobre a expertise musical dos participantes, bem como questões relacionadas ao próprio experimento. Cada sessão experimental durava aproximadamente 25 minutos.

Análise dos dados: foi aplicado um teste Chi-Quadrado para verificar a porcentagem de respostas referentes aos julgamentos emocionais dos participantes em relação a cada trecho musical ouvido. Nos casos em que um mesmo trecho musical obteve uma porcentagem de respostas diferente entre os grupos (músicos e não músicos), foi feita uma correlação de Spearman para verificar qual emoção obteve o maior número de respostas dentro de cada grupo. Foram consideradas diferenças estatísticas para o nivel de $p$ igual ou menor que 0,05 . Outra análise foi feita a partir da reorganização dos dados, da seguinte maneira: cada associação emocional dos participantes foi substituida por um valor numérico de 1 ou -1 , dependendo dos valores de arousal ou de valência afetiva encontrados. Assim, respostas emocionais de Alegria foram substituídas pelo par 1 e 1, porque a Alegria pode ser entendida como sendo uma emoção com alto índice de arousal (1) e valência afetiva positiva (1); respostas emocionais de Serenidade foram substituídas pelo par -1 e 1, porque a Serenidade pode ser entendida uma emoção com baixo índice de arousal e valência afetiva positiva; da mesma forma, respostas da categoria emocional Medo/Raiva foram substituídas pelo par 1 e -1 , porque esta categoria emocional sugere alto indice de arousal e valência afetiva negativa; e, finalmente, respostas emocionais de Tristeza foram substituidas pelo par $-1,-1$, porque esta emoção sugere um baixo índice de arousal e valência afetiva negativa (RUSSEL, 1980). Este tipo de análise possibilitou o cálculo de um valor numérico médio de arousal e de valência afetiva para cada um dos 30 trechos musicais empregados neste estudo, para ambos os grupos (músicos e não músicos). Ao final da análise, os valores numéricos encontrados foram distribuídos em um referencial cartesiano, elaborado a partir do Modelo Circumplexo de RUSSEL (1980).

\section{3 - Resultados}

0 Ex.2 mostra a porcentagem das associações emocionais dos trechos musicais apresentados aos participantes músicos e não músicos.

De acordo com o Ex.2 a maioria dos trechos musicais foi associada a uma emoção dominante para ambos os grupos (vinte e dois trechos musicais). Os maiores indices de porcentagem obtidos por uma única emoção foram encontrados para os trechos $4,10,13,14,18,24$, 27 e 28. Considerou-se uma emoção dominante quando uma mesma emoção, para determinado trecho musical, apresentou índices de escolha maiores que 50\% pelos participantes. No entanto, alguns trechos não foram associados somente a uma única emoção (oito casos, em ambos os grupos). Os índices de porcentagem que mais ilustram esta não associação são aqueles obtidos para os trechos 7, 9, 16, 19 e 30 .

De maneira geral, a Alegria foi a emoção associada com maior frequência (com média percentual de $30 \%$ para o grupo Músicos e 31\% para o grupo Não Músicos). A emoção Serenidade obteve média percentual de $29 \%$ para o grupo Músicos e 25\% para o grupo Não Músicos. A emoção Tristeza obteve média percentual de 23\% das associações para ambos os grupos. A categoria emocional Medo/Raiva obteve média percentual de 17\% para o grupo Músicos e de apenas 21\% para 0 grupo Não Músicos.

Dentre os 30 trechos musicais, apenas dois apresentaram diferenças significativas entre os julgamentos emocionais de um grupo e outro: os de número 5 e 17. Foi feita uma 
Correlação de Spearman para verificar qual emoção foi mais característica dentro de cada grupo, em relação a estas duas peças musicais. Assim, a música número 05 foi associada à Serenidade para ambos os grupos, porém, com indices diferentes sobre esta mesma emoção $\left[X^{2}(1)\right.$ $\left.=12,522, p=0,006 ; C_{s}=-0,342 ; p=0,055\right]$. A música número 17 foi associada à Tristeza para o grupo Músicos e a Medo/Raiva para o grupo Não Músicos, $\left[X^{2}(2)=9,6\right.$, $\left.p=0,008 ; C_{S}=-0,477 ; p=0,006\right]$.

Para todas as outras músicas apresentadas, não houve diferenças estatísticas significativas dos julgamentos emocionais entre os grupos, ou seja, as emoções foram processadas de forma semelhante entre os dois grupos.
0 Ex.3 e o Ex.4 mostram os valores médios de arousal e de valência afetiva das associações emocionais de ambos os grupos, distribuídos em um espaço cartesiano, semelhante ao Modelo Circumplexo de RUSSEL (1980).

Os resultados indicam que a música desencadeou emoções específicas nos ouvintes. Os resultados indicam também que as emoções específicas desencadeadas em músicos e não músicos foram processadas de forma parecida. Porém, o Ex.3 mostra que as respostas emocionais do grupo Músicos foram mais homogêneas em relação às respostas emocionais do grupo Não Músicos, ou seja, houve maior concordância de respostas sobre uma mesma emoção no primeiro grupo em relação

\begin{tabular}{|c|c|c|c|}
\hline & & Músicos & Não Músicos \\
\hline Música & Título & Associaçăo emocional & Associação emocional \\
\hline 1 & Also sprach Zarathustra (Strauss) & Medo / Raiva (56,3\%) & Medo / Raiva (56,3\%) \\
\hline 2 & Waltz n 03 (Chooin) & Serenidade $(56,3 \%)$ & Serenidade $(75 \%)$ \\
\hline 3 & Piano Concerto Adágio (Mozart) & Tristeza $(56,3 \%)$ & Tristeza $(87,5 \%)$ \\
\hline 4 & Violin Concerto Adágio (Brahms) & Serenidade $(75 \%)$ & Serenidade $(75 \%)$ \\
\hline 5 & Sonata A for Harpsichord (Scarlatiti) & Serenidade $(100 \%)^{*}$ & Serenidade $(43,8 \%)^{*}$ \\
\hline 6 & Träumerei $n^{0} 07$ (Schumann) & Serenidade $(56,3 \%)$ e Tristeza $(43,8 \%)$ & Tristeza $(56,3 \%)$ e Serenidade $(43,8 \%)$ \\
\hline 7 & Sonata for piano n ${ }^{\circ} 03$ (Prokofièv) & $\operatorname{ALE}(31,3 \%), \operatorname{MRV}(31,3 \%), \operatorname{SER}(18,8 \%), \operatorname{TR}(18,8 \%)$ & $\operatorname{MRV}(43,8 \%), \operatorname{SER}(31,3 \%), \operatorname{ALE}(25 \%)$ \\
\hline 8 & Trio 2 for piano, violin and cello (Shostakovitch) & Tristeza (62,5\%) & Tristeza $(56,3 \%)$ \\
\hline 9 & Tristan, act 03 (Wagner) & $\operatorname{TRI}(68 \%), \operatorname{MRV}(18,8 \%)$ e SER $(12,5 \%)$ & Tristeza (50\%) e Medo / Raiva (50\%) \\
\hline 10 & Symphony Bdur, Andante (Haydn) & Alegria $(87,5 \%)$ & Alegria $(87,5 \%)$ \\
\hline 11 & Poème Symphonique (Liszt) & $\operatorname{TRI}(56,3 \%), \operatorname{SER}(25 \%)$ EMRV $(18,8 \%)$ & $\operatorname{SER}(56,3 \%), \operatorname{TR}(37,5 \%) \operatorname{EMRV}(6,3 \%)$ \\
\hline 12 & Gnossiènne n ${ }^{\circ} 02$ (Satie) & Tristeza $(68,8 \%)$ & Tristeza $(81,3 \%)$ \\
\hline 13 & Hungarian Rapsody n 02 (Liszt) & Alegria $(100 \%)$ & Alegria $(93,8 \%)$ \\
\hline 14 & That certain feeling (Gershwin) & Alegria $(100 \%)$ & Alegria (100\%) \\
\hline 15 & Italian Symphony, 1st mov. (Mendelsohn) & Alegria $(81,3 \%)$ & Alegria $(68,8 \%)$ \\
\hline 16 & Prèlude $n^{0} 24$ (Chopin) & $\operatorname{TRI}(43,8 \%), \operatorname{SER}(43,8 \%), \operatorname{MRV}(12,5 \%)$ & $\operatorname{TRI}(43,8 \%), \operatorname{SER}(25 \%), \operatorname{MRV}(25 \%) \operatorname{EALE}(6,3 \%)$ \\
\hline 17 & Tasso Lamento \& Triomfo (Liszt) & Tristeza $(56,3 \%)^{*}$ & Medo / Raiva $(87,5 \%)^{*}$ \\
\hline 18 & Tod and Verklärung 7' to 7'36 (Strauss) & Medo / Raiva (87,5\%) & Medo / Raiva (93,8\%) \\
\hline 19 & Violin Sonata (Bach) & $\operatorname{SER}(43,8 \%), \operatorname{MRV}(25 \%), \operatorname{TR}(18,8 \%)$ e ALE $(12,5 \%)$ & $\operatorname{ALE}(37,5 \%), \operatorname{MRV}(25 \%), \operatorname{SER}(18,8 \%)$ e TRI $(18,8 \%)$ \\
\hline 20 & Scherzo, presto - A truta (Schubert) & Alegria $(62,5 \%)$ & Alegria $(81,3 \%)$ \\
\hline 21 & Suite française G - Sarabande (Bach) & Serenidade (50\%) e Tristeza (50\%) & Serenidade $(81,3 \%)$ e Tristeza $(18,3 \%)$ \\
\hline 22 & Duetto for two flutes in F, lamentabile (Bach) & Alegria $(62,5 \%)$ & Alegria $(62,5 \%)$ \\
\hline 23 & Trio for piano, violin and horm, moderato (Shostakovitch) & Alegria $(81,3 \%)$ & Alegria $(62,5 \%)$ \\
\hline 24 & Petrouchka (Stravinsky) & Alegria $(75 \%)$ & Alegria $(87,5 \%)$ \\
\hline 25 & Enwartung (Schöenberg) & Tristeza $(75 \%)$ & Tristeza (68,8\%) \\
\hline 26 & Trio 2 for violin, cello e piano - moderato (Shostakovitch) & Medo / Raiva (62,5\%) & Medo / Raiva (56,3\%) \\
\hline 27 & Totentanz (Liszt) & Medo / Raiva (100\%) & Medo / Raiva (93,8\%) \\
\hline 28 & 0 tambor dos granadeiros (Chapi) & Alegria $(93,8 \%)$ & Alegria $(75 \%)$ \\
\hline 29 & Violin romance (Beethoven) & Serenidade $(81,3 \%)$ & Serenidade $(56,3 \%)$ \\
\hline 30 & Valse in E minor - vivace (Chopin) & $\operatorname{SER}(50 \%), \operatorname{ALE}(31,3 \%), \operatorname{TR}(12,5 \%), \operatorname{MRV}(6,3 \%)$ & $\operatorname{ALE}(43,8 \%), \operatorname{SER}(37,5 \%), \operatorname{MRV}(12,5 \%), \operatorname{TR}(6,3 \%)$ \\
\hline
\end{tabular}

Ex.2 - Tabela com porcentagem de associações emocionais dos participantes (músicos e não músicos), em relação a cada trecho musical apresentado. 0 asterisco indica diferenças estatísticas entre os grupos. 


\section{Músicos}

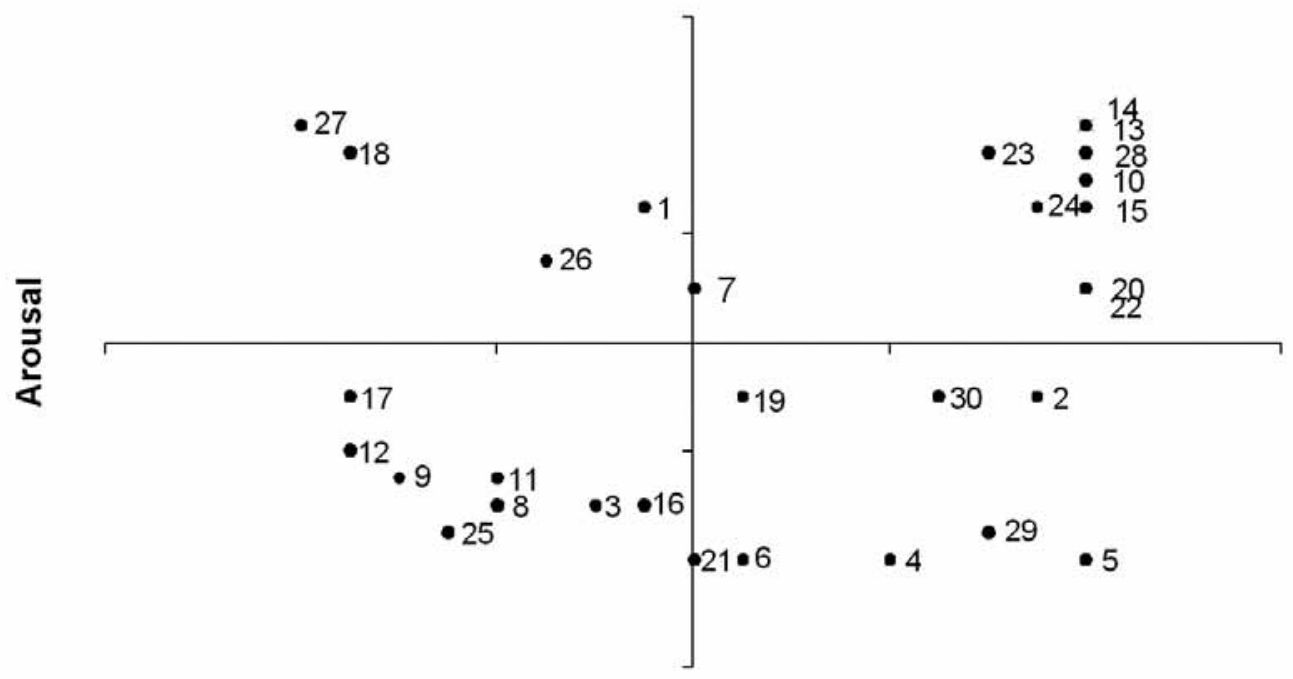

Valência Afetiva

Ex.3 - Distribuição dos trechos musicais empregados neste estudo dentro do Modelo Circumplexo de Russel, de acordo com as emoções percebidas por participantes músicos. Cada trecho musical está indicado por um número (ver Ex.1).

\section{Não Músicos}

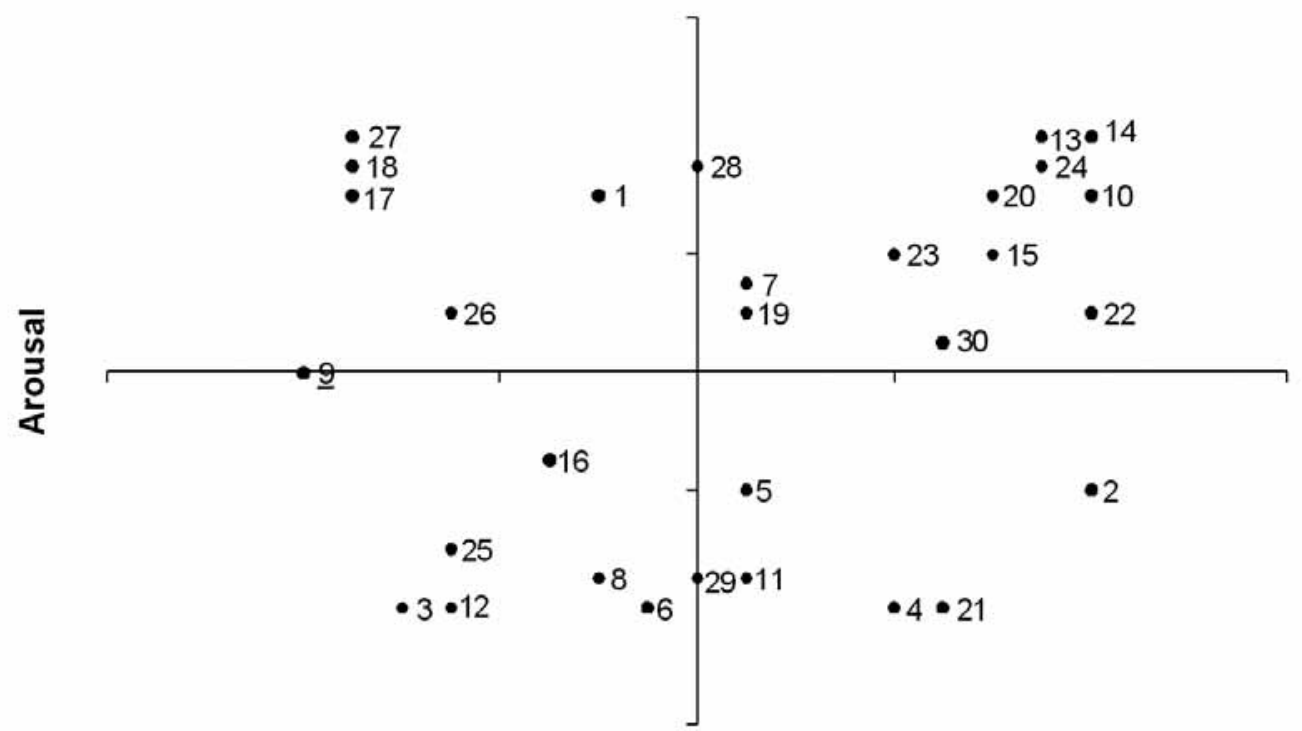

Valência Afetiva

Ex.4- Distribuição dos trechos musicais empregados neste estudo dentro do Modelo Circumplexo de Russel, de acordo com as emoções percebidas por participantes não músicos. Cada trecho musical está indicado por um número (ver Ex.1). 
ao segundo. Portanto, os agrupamentos das associações emocionais do grupo Músicos em relação aos trechos musicais desencadeadores de uma mesma emoção foram mais salientes do que os agrupamentos emocionais do grupo Não Músicos.

\section{4 - Discussão}

0 presente estudo teve como objetivo mensurar respostas emocionais de músicos e não músicos a trechos musicais do repertório erudito ocidental. Este assunto já foi abordado por diversos autores (HEVNER, 1935, 1936; ROBAZZA; MACALUSO; D'URSO, 1994; SLOBODA; JUSLIN, 2001; JUSLIN; LAUKKA, 2004; BIGAND et al., 2005). Os dados aqui obtidos mostram que alguns trechos musicais empregados desencadearam emoções específicas em ouvintes brasileiros, tanto em músicos quanto em não músicos. Este resultado pôde ser corroborado por meio dos questionários complementares aplicados após a coleta de dados, que apresentaram relatos de alguns participantes mostrando dúvidas para associar certos trechos musicais a uma emoção específica. Este dado converge com outro estudo que empregou os mesmos trechos musicais em participantes europeus (BIGAND et al., 2005). No entanto, outros trechos não desencadearam uma única emoção específica nos mesmos ouvintes. Essa não associação pode ter ocorrido devido à presença de estruturas musicais distintas (em alguns casos opostas) em um mesmo trecho musical, o que pode ter gerado o desencadeamento de emoções ambíguas nos participantes.

Com relação ao tipo do teste empregado no presente estudo, BIGAND et al. (2005) elaboraram uma tarefa experimental que consistia em reagrupar os trechos musicais característicos de uma mesma emoção, definindo assim categorias emocionais sem recorrer à linguagem verbal, abrindo mão de um léxico emocional, que se sabe variável em função do nível de conhecimento musical e das aptidões verbais de cada um. Duas semanas após essa "categorização livre", os mesmos participantes refizeram a tarefa com os mesmos trechos musicais. Apesar de os resultados indicarem as categorizações emocionais Alegria, Tristeza, Serenidade, Medo e Raiva como sendo os léxicos emocionais mais frequentemente encontrados, outros léxicos como Ternura, Nostalgia e Curiosidade também foram encontrados. No presente estudo, os questionários aplicados após o estudo indicaram que alguns participantes tiveram dúvidas para associar certos trechos musicais a uma única emoção, alegando que poderia existir a possibilidade de escolha outros léxicos não empregados no estudo, como Melancolia, Paixão, Sono e Amor. Portanto, o uso de apenas quatro possibilidades de escolha (Alegria, Tristeza, Serenidade, Medo /Raiva) pode ter limitado aos participantes a escolha de léxicos mais precisos referente às emoções percebidas de alguns trechos musicais empregados.

JUSLIN e LAUKKA (2004) sugerem certas estruturas musicais que frequentemente estão associadas com as emoções musicais de base, por exemplo: músicas executadas em andamentos rápidos, com pouca variabilidade de andamento, em modo maior, com harmonia simples e consonante, com pouca variação de dinâmica, com melodia ascendente e com contorno melódico acentuado (entre outras), normalmente serão associadas à Alegria. Da mesma forma, há uma série de outras estruturas musicais também associadas às outras emoções musicais de base, como Tristeza, Serenidade, Medo/Raiva. Assim, outra hipótese a ser considerada para explicar o fato de alguns trechos musicais não terem sido associados a uma única emoção é a de que alguns trechos musicais poderiam ter estruturas musicais encontradas por estes autores que pertencessem a categorias emocionais distintas. Por exemplo: o trecho musical 30 (Valse in E minor, de F. Chopin), que não foi associado a nenhuma emoção específica por ambos os grupos, tinha um andamento rápido (estrutura considerada pelos autores como sendo associada predominantemente à Alegria), estava em modo menor (estrutura considerada pelos autores como sendo associada predominantemente à Tristeza), articulações de staccato (estrutura considerada pelos autores como sendo associada predominantemente à Raiva) e súbitos ataques nas notas da melodia (estrutura considerada pelos autores como sendo associada predominantemente à emoção Medo). Portanto, esta mistura de elementos estruturais emocionais dentro de um mesmo trecho musical pode ter gerado uma ambiguidade nas respostas emocionais dos ouvintes.

Outra questão que foi investigada pelo presente estudo foi em relação à influência da expertise musical sobre respostas emocionais à música. A literatura tem mostrado provas de que músicos processam a informação musical de forma mais "refinada" que os não músicos (WATERMANN, 1996; KOELSCH; GUNTER; FRIEDERICI; SCHRÖEGER, 2000; SCHERER; ZENTNER, 2001; GALVÃO, 2006). No entanto, os estudos acerca desta questão têm mostrado que não músicos respondem a mudanças sutis na estrutura musical de forma comparável aos músicos (BIGAND; POULIN-CHARRONAT, 2006). Assim, se for considerado que a resposta emocional à música está, pelo menos em parte, enraizada no processamento das estruturas musicais (BIGAND et al., 2005), uma hipótese que pode explicar o processamento da informação musical dos músicos como sendo mais "refinado" do que o dos não músicos é a de que, no presente estudo, o primeiro grupo pode ter identificado e nomeado as emoções musicais de forma mais rápida do que 0 segundo grupo. Assim, pelo fato de lidarem com a experiência musical de forma mais analítica, em função do tempo de estudo (aprendizagem) musical, os músicos parecem estar mais treinados para tarefas relacionadas à percepção de emoções desencadeadas durante uma escuta musical. No presente estudo, ambos os grupos foram respondendo de forma emocional coerente aos trechos musicais empregados. Isto é indicado pelo fato de que, dos 30 trechos musicais empregados no presente estudo, 28 obtiveram respostas emocionais semelhantes 
entre os grupos. Porém, de forma geral, houve mais consistência nas respostas emocionais dos músicos em relação às respostas emocionais dos não músicos. Isso sugere que houve mais respostas emocionais relacionadas a um mesmo trecho musical para o grupo Músicos do que para o grupo Não Músicos. Este dado é coerente com outros estudos sobre a análise da expertise musical sobre respostas emocionais (BIGAND et al., 2005; BIGAND; FILIPIC; LALITTE, 2006).

Os dados deste estudo permitem alguns esclarecimentos acerca dos processos psicológicos que permeiam 0 processamento das emoções musicais de trechos musicais do repertório erudito ocidental, durante uma escuta musical, em sujeitos ocidentais. Em alguns casos, como no estudo realizado por BIGAND et al. (2005), os resultados mostram que as emoções musicais dependeram mais do conteúdo cognitivo da estrutura musical de uma obra do que da história pessoal de cada um. Esta afirmação pode ser confirmada pelo fato de alguns trechos musicais terem sido associados a uma única emoção específica por ambos os grupos de participantes. Na maioria dos trechos musicais em que esta única associação ocorreu, a emoção associada foi a Alegria. Em contrapartida, os resultados do presente estudo também apontam dados que mostram o contrário: alguns trechos musicais não foram associados a uma única emoção específica por ambos os grupos de participantes. E em dois casos, os resultados do presente estudo sugerem um espaço intermediário entre o conteúdo cognitivo da estrutura musical e a cognição das respostas emocionais baseadas nas experiências subjetivas de cada participante: este enunciado pode ser confirmado a partir das associações a uma única emoção específica em porcentagens mais modestas para ambos os grupos e associações a duas emoções equivalentes entre grupos.

Apesar de as respostas emocionais de músicos e não músicos terem sido parecidas, é possivel supor que em alguns casos, a expertise musical pode determinar a qualidade das respostas. No presente estudo, este enunciado pode ser confirmado porque as respostas emocionais de músicos e não músicos para dois trechos musicais empregados foram processadas de forma diferente. Assim, os resultados indicaram diferenças estatísticas entre grupos para os trechos musicais 5 e 17. Segundo HARGREAVES e CASTELL (1986), a familiaridade de um indivíduo ao evento musical apreciado (denominada "aculturação") está relacionada com o seu tempo de vida, uma vez que ele é exposto a uma gama maior de eventos musicais conforme vai ficando mais velho. Em um estudo realizado sobre a noção de familiaridade de indivíduos ocidentais com a música tonal ocidental, estes autores sugerem que os efeitos da familiaridade/aculturação interagem com a complexidade da música em questão. Segundo HARGREAVES e CASTELL (1986), conforme as pessoas se tornam mais familiares com um evento a ser apreciado, este evento se torna mais previsivel e, consequentemente, menos subjetivamente complexo. A consequência disso é a diminuição do arousal direcionado a este evento. Assim, estímulos complexos e desencadeadores de altos niveis de arousal "precisam" tornar-se mais familiares para alcançar níveis moderados de arousal; ao contrário, estímulos simples, com niveis de arousal relativamente baixos, provavelmente desencadearão níveis de arousal moderados a partir de níveis de familiaridade muito menores (HEYDUCK, 1975). As respostas emocionais associadas aos trechos musicais 5 e 17 confirmam esta hipótese. No caso do trecho musical número 5 , apesar de ele ter sido predominantemente associado à emoção Serenidade por ambos os grupos, todos os músicos associaram-no a esta emoção, enquanto que nem metade dos músicos o categorizou dessa forma. No caso do trecho musical número 17, ele foi associado predominantemente à emoção Tristeza pelos músicos e à categoria emocional Medo / Raiva pelos não músicos. A Tristeza é uma emoção que desencadeia níveis de arousal menores do que as emoções Medo ou Raiva (RUSSEL, 1980). Portanto, tanto para o trecho músical número 5 , como para o trecho musical número 17 , os níveis de arousal encontrados para cada trecho musical foram menores para os músicos do que para os não músicos.

Os dados do presente estudo sugerem que possam existir mecanismos diferenciados (ou paralelos) que parecem reger o processamento cognitivo de respostas emocionais de indivíduos ocidentais à música de sua própria cultura: um primeiro mecanismo parece estar relacionado a respostas emocionais comuns, baseadas na cognição da estrutura da obra musical; um outro mecanismo parece estar relacionado às diferenças individuais; e um terceiro mecanismo parece estar relacionado à expertise musical. Uma investigação sistemática sobre os fatores psicológicos envolvidos em cada tipo de mecanismo de resposta emocional à música pode trazer contribuições significativas acerca dos processos psicológicos que regem as emoções musicais. 


\section{5 - Referências}

BALKWILL, L. L.; THOMPSON, W. F. A cross-cultural investigation of the perception of emotion in music: psychophysical and cultural cues. Music Perception, v.17, n.1, p.43-64, 1999.

BERLYNE, D. The new experimental aesthetics: steps toward an objective psychology of aesthetics appreciation. Washington, D.C.: Hampshire, 1974.

BIGAND, E.; FILIPIC, S.; LALITTE, P. The time course of emotional response to music. Annals of the New Academic of Sciences, v.1060, p.429-437, 2006.

BIGAND, E.; POULIN-CHARRONAT, B. Are we all "experienced listeners"? Cognition, v.100, n. 1, p.100-130, 2006.

BIGAND, E.; VIEILLARD, S.; MADURELL, F.; MAROZEAU, J.; DACQUET, A. Multidimensional scaling of emotional responses to music: the effect of musical expertise and of the duration of the excerpts. Cognition and Emotion, v.19, n.8, p.1113-1139, 2005.

COCENAS-SILVA, R.; BUENO, J. L. 0.; MOLIN, P.; BIGAND, E. Multidimensional scaling of musical time estimations. Perceptual and Motor Skills, v.112, p.737-748, 2011.

DALLA BELLA, S.; PERETZ, I.; ROUSSEAU, L.; GOSSELIN, N.; AYOTTE, J.; LAVOIE, A. Development of the happy-sad distinction in music appreciation - Does tempo emerge earlier than mode? Annals of New York Academy of Sciences, v.930, p.436-438, 2001.

GABRIELSSON, A.; JUSLIN, P. Emotional expression in music. In DAVIDSON, R. J.; K. R. SCHERER; H. H. GOLDSMITH (Eds.). Handbook of Affective Sciences. New York: Oxford University Press, p.503-534, 2003.

GABRIELSSON A.; LINDSTRÖM, E. The influence of musical structure on emotional expression. IN: JUSLIN, P. N.; SLOBODA, J. J. (Eds.). Music and emotion: theory and research. New York: Oxford University Press, p.223-248, 2001.

GALVÃO, A. Cognição, emoção e expertise musical. Psicologia: Teoria e Pesquisa, v. 22, n. 2, p.169-174, 2006.

HARGREAVES, D.; CASTELL, K. C. Development of liking for familiar and unfamiliar melodies. In: INTERNATIONAL SEMINAR OF THE INTERNATIONAL SOCIETY FOR

MUSIC EDUCATION, 11. 1986, Frankfurt, Germany. Paper presented at the Eleventh International Seminar of the International Society for Music Education. Frankfurt, Germany, 1986.

HEVNER, K. Expression in music: a discussion of experimental studies and theories. Psychological Review, v.42, p.186-204, 1935.

HEVNER, K. Experimental studies of the elements of expression in music. American Journal of Psychology, v.48, p.246-268, 1936.

HEYDUCK, R. G. Rated preference for musical composition as it relates to complexity and exposure frequency. Perception and Psychophysics, n.17, p.84-91, 1975.

JØRGENSEN, H. The psychology of the music experience. Oslo: Norsk Musikforlag, 1988.

JUSLIN, P.; LAUKKA, P. Expression, perception and induction of musical emotions: a review and a questionnaire study of everyday listening. Journal of New Music Research, v.33, n.3, p.217-238, 2004.

KOELSCH, S.; GUNTER, T.; FRIEDERICI, A. D.; SCHRÖEGER, E. S. Brain indices of music processing: 'nonmusicians' are musical. Journal of Cognitive Neurosciences, v.12, p.520-541, 2000.

LARSEN, J. T; DIENER, E. Promisses and problems with the circumplex model of emotion. In: CLARKE, M. S. (Ed.). Review of personality and Social Psychology. Newbury Park: Sarge, 1992, v.14, p.25-59.

RAMOS, D.; BUENO, J. L. 0.; BIGAND, E. Manipulating ecclesiastic musical modes and tempo results in continuous changes in perceived musical emotion along arousal and valence dimensions. Brazilian Journal of Biological and Medical Research, v.44, p.106-114, 2011.

ROBINSON, J. Music and meaning. Ithaca, NY: Cornell University Press, 1997.

ROBAZZA, C.; MACALUSO, C.; D'URSO, V. Emotional reactions to music by gender, age and expertise. Perceptual and Motors Skills, v.79, p.939-944, 1994.

RUSSEL, P. A. Affective space is bipolar. Journal of Personality and Social Psychology, v.37, p.345-356, 1979.

RUSSEL, P. A. A circumplex model of affect. Journal of Personality and Social Psychobiology, v.39, p.1161-1178, 1980.

SCHERER, K. R.; ZENTNER, M. R. Emotional effects of music: production rules. In: JUSLIN, P. N.; SLOBODA, J. A. (Eds.). Music and emotion: theory and research. New York: Oxford University Press, 2001, p.361-392.

SLOBODA, J.; JUSLIN, P. Music and emotion: theory and research. New York: Oxford University Press, 2001.

WATERMAN, M. Emotional responses to music: implicit and explicit effects in listeners and performers. Psychology of Music, v.24, p.53-67, 1996. 


\section{Nota}

1 Para realização desta pesquisa, D. Ramos obteve bolsa de Doutorado (Capes) e J. L. O. Bueno obteve bolsa de Pesquisador 1 e Auxilio para Pesquisa (CNPq). Agradecemos o apoio técnico de João Luis Segalla Borin.

Danilo Ramos é Bacharel em Música Popular pela UNICAMP (Habilitação: piano), mestre e doutor em Psicologia pela USP-Ribeirão Preto. Concluiu em 2009 um Pós-doutorado em Cognição Musical pela Université de Bourgogne, em Dijon (França). Atualmente, é Professor Adjunto do Departamento de Artes da Universidade Federal do Paraná e pesquisador na área de Cognição Musical (subáreas: Emoções Musicais e Percepção do tempo durante o discurso musical). É um dos líderes do grupo de pesquisa intitulado Processos Formativos e Cognitivos em Educação Musical (CNPq).

José Lino Oliveira Bueno é Professor Titular de Psicobiologia da Faculdade de Filosofia, Ciências e Letras de Ribeirão da Universidade de São Paulo. Coordenador do Laboratório de Processos Associativos, Controle Temporal e Memória e do Centro de Estética Experimental, sua pesquisa envolve estudos sobre controle temporal e tempo subjetivo, investigando: a) a influência de estimulação musical e visual sobre a percepção temporal humana; b) os processamentos temporais e mecanismos de aprendizagem complexa em animais e humanos; c) as relações entre a ativação neuronal do hipocampo, da amígdala e suas conexões com o comportamento. 